\title{
Maze procedure in the Marfan syndrome
}

Hiroyuki Nakajima, MD, Ko Bando, MD, Soichiro Kitamura, MD, Junjiro Kobayashi, MD, Kazuo Niwaya, MD, and Osamu Tagusari, MD, Osaka, Japan

W hen a successful maze procedure provides normal sinus rhythm, avoidance of mechanical valve will provide active life without anticoagulation. This is especially true among patients with Marfan syndrome, because most of the late mortality and morbidity after cardiac surgery in Marfan syndrome have been related to the prosthetic valve, anticoagulation therapy, and aortic lesions, including bleeding or dissection. ${ }^{1}$ However, the maze procedure has not usually been performed with reconstruction of the combined aortic and mitral valves, on the assumption that prolonged bypass time could result in adverse outcomes. We report here the successful surgical treatment of a patient with aortic and mitral insufficiency and chronic atrial fibrillation.

\section{Clinical Summary}

A 43-year-old woman had a family history of Marfan syndrome. On the electrocardiogram, sustained atrial fibrillation with an $f$

From the Department of Cardiovascular Surgery, National Cardiovascular Center, Osaka, Japan.

Received for publication Aug 21, 2002; accepted for publication Sept 25, 2002.

Address for reprints: Ko Bando, MD, Department of Cardiovascular Surgery, National Cardiovascular Center, 5-7-1 Fujishirodai, Suita, Osaka 565-8565, Japan (E-mail: kobando@ @sp.ncvc.go.jp).

J Thorac Cardiovasc Surg 2003;125:1539-40

Copyright $\odot 2003$ by The American Association for Thoracic Surgery

$0022-5223 / 2003 \$ 30.00+0$

doi:10.1016/S0022-5223(03)00058-8 wave of $0.15 \mathrm{mV}$ in the $\mathrm{V}_{1}$ lead was found. On echocardiography, severe mitral regurgitation from both anterior and posterior leaflet prolapse, primarily in the posteromedial portion, was detected. The sinus of Valsalva was dilated to $55 \mathrm{~mm}$ in diameter, and the aortic annulus was dilated to $35 \mathrm{~mm}$ (Figure 1). Aortic regurgitation was mild.

Through a right-sided left atriotomy, the mitral valve was exposed. We used paracommissural edge-to-edge sutures and placed a 29-mm Duran ring (Medtronic, Inc, Minneapolis, Minn). Subsequently, we performed cryoablation on the left and right atria for the modified maze procedure (Figure 2).

The aortic valve leaflets appeared normal on gross inspection. We performed reimplantation of the aortic valve with a $28-\mathrm{mm}$ Gelsoft graft (Vascutek Ltd, Inchinnan, United Kingdom). The patient successfully resumed sinus rhythm, and mechanical valve replacement was avoided. She therefore did not require anticoagulation.

\section{Discussion}

As aortic surgery has improved, the life span of patients with Marfan syndrome has been prolonged, but it is still not satisfactory. ${ }^{1-3}$ Avoidance of mechanical valves and anticoagulation therapy may improve quality of life for these patients. The necessary reconstructive procedures may be technically demanding, however, and selection of appropriate patients may be difficult. In the aortic position, valve-sparing procedures have been recommended for patients with normal leaflets without the use of a mechanical valve in the mitral position. ${ }^{4}$ In the mitral position, understanding of the complicated anatomy of diseased mitral valve has improved the quality of mitral valve repair, and intermediate-term durability
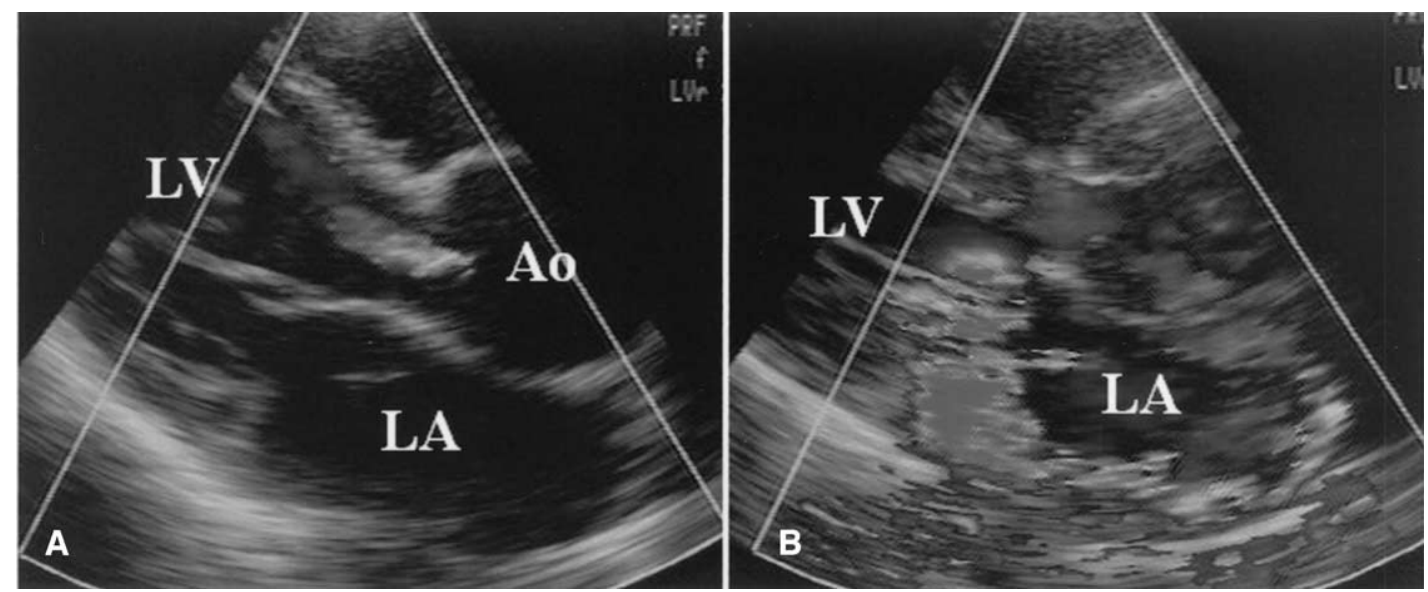

Figure 1. Preoperative transthoracic echocardiograms. $A$, Aortic regurgitation was mild in central area of valve orifice. Leaflet prolapse was not present. $B$, Severe mitral regurgitation resulted from anterior and posterior leaflet prolapse. Left atrial dimension was $50 \mathrm{~mm}$. $L V$, Left ventricle; Ao, aorta; $L A$, left atrium. 

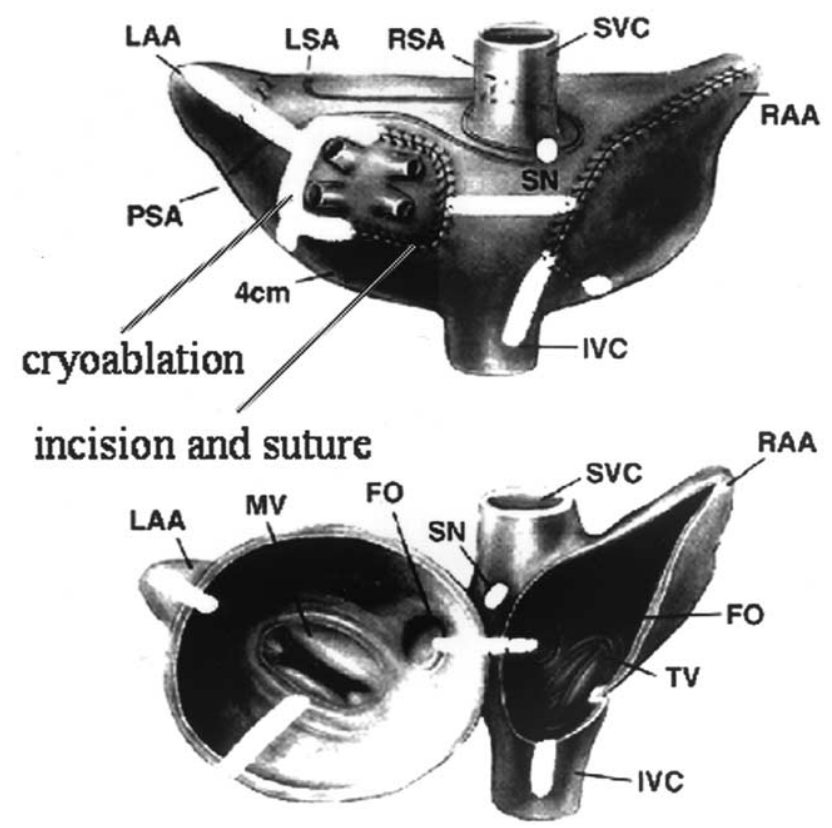

Figure 2. Our current modification of maze procedure. $L A A$, Left atrial appendage; $L S A$, left sinus node artery; $R S A$, right sinus node artery; $S V C$, superior vena cava; $R A A$, right atrial appendage; $S N$, sinus node; $P S A$, posterior sinus node artery; $I V C$, inferior vena cava; $\boldsymbol{M V}$, mitral valve; $F O$, fossa ovalis; $T V$, tricuspid valve. From Bando K, Kobayashi J, Kosakai Y, Hirata M, Sasako Y, Nakatani S, et al. Impact of Cox maze procedure on outcome in patients with atrial fibrillation and mitral valve disease. $J$ Thorac Cardiovasc Surg. 2002;124:577. Reprinted with permission. has been reported as similar to that seen with non-Marfan degenerative disease. $^{2,3}$

In our case, successful repair of valves and sinus rhythm were all required to avoid anticoagulation therapy after the operation. Our current maze procedure consists of pulmonary venous isolation and interruption of the macro reentry circuit with cryoablation through a standard right-sided left atriotomy. ${ }^{5}$ With this technique, crossclamp time was reduced by 30 minutes yet achieved a recovery rate of sinus rhythm comparable to that seen with the conventional maze procedure in mitral valve disease. ${ }^{5}$

Most patients with Marfan syndrome are relatively young at the maze operation. The aggressive surgical approach may therefore be valuable to decrease the late complications associated with anticoagulation, thus improving quality of life.

\section{References}

1. Finkbohner R, Johnston D, Crawford ES, Coselli J, Milewicz DM. Marfan syndrome: long-term survival and complications after aortic aneurysm repair. Circulation. 1995;91:728-33.

2. Fuzellier JF, Chauvaud SM, Fornes P, Berrebi AJ, Lajos PS, Bruneval $\mathrm{P}$, et al. Surgical management of mitral regurgitation associated with Marfan's syndrome. Ann Thorac Surg. 1998;66:68-72.

3. Gillinov AM, Hulyalkar A, Cameron DE, Cho PW, Greene PS, Reitz BA, et al. Mitral valve operation in patients with the Marfan syndrome. J Thorac Cardiovasc Surg. 1994;107:724-31.

4. David TE. Current practice in Marfan's aortic root surgery: reconstruction with aortic valve preservation or replacement? What to do with the mitral valve? J Card Surg. 1997;12:147-50.

5. Bando K, Kobayashi J, Kosakai Y, Hirata M, Sasako Y, Nakatani S, et al. Impact of Cox maze procedure on outcome in patients with atrial fibrillation and mitral valve disease. J Thorac Cardiovasc Surg. 2002; 124:575-83. 